\title{
Economic policy uncertainty, investor sentiment and financial stability-an empirical study based on the time varying parameter-vector autoregression model
}

\author{
Xin-Zhou Qi ${ }^{1} \cdot$ Zhong Ning $^{2} \cdot$ Meng Qin $^{3}$
}

Received: 28 July 2021 / Accepted: 9 December 2021 / Published online: 28 December 2021

(c) The Author(s), under exclusive licence to Springer-Verlag GmbH Germany, part of Springer Nature 2021

\begin{abstract}
This paper applies the time varying parameter-vector autoregression model to explore the dynamic relationship between economic policy uncertainty, investor sentiment and financial stability in China in different periods and at different time points. The empirical results show that economic policy uncertainty has an obvious negative impact on investor sentiment before 2012 and financial stability in the short term, and the influence of economic policy uncertainty on investor sentiment is greater than that economic policy uncertainty on financial stability. These influences were more significant during the period of the global financial crisis in 2008. Moreover, investor sentiment had a positive and gradually increasing effect on financial stability, while after 2010, the positive impact gradually weakened. Furthermore, economic policy uncertainty is negatively affected by financial stability, and the effect of financial stability on investor sentiment is positive. In terms of mediating effects, economic policy uncertainty has an indirect impact on financial stability through investor sentiment and vice versa. This paper provides a new solution to economic problems explored in behavioral finance research. Additionally, Chinese government agencies can achieve the goal of preventing financial crises and maintaining financial stability by monitoring investor sentiment and implementing targeted economic policies.
\end{abstract}

Keywords Economic policy uncertainty - Investor sentiment · Financial stability · Time varying parameter-vector autoregression model

JEL Classification E60 - G18

\section{Introduction}

The main goal of this paper is to explore the dynamic relationships between economic policy uncertainty, investor sentiment and financial stability in China. The

Extended author information available on the last page of the article 
United States subprime mortgage crisis broke out in August 2007 and quickly swept the global financial market, which has had a significant negative impact on the global economy. Since economic globalization has strengthened the bonds between countries, to minimize the influence of the financial crisis, the effective formulation of relevant economic policies has become the goal of departments and scholars in various countries (Baker et al. 2016). A round of economic policies can promote social stability and steady economic growth. However, the augmentation of economic policy uncertainty could lead to deviation in investors' expectations of future returns and risks, resulting in social unrest and financial instability, signifying that economic policy uncertainty may affect investor sentiment and financial stability. In addition, excessive economic innovation policies have enabled the securitization of mortgage loans, spreading risk rapidly to the entire market, which has become extremely unstable. A series of policies lead investors to have different expectations of the market, thus resulting in different investment decisions. Owing to the performance of investors, which eventually causes changes in the financial market, economic policy uncertainty has acted on investor sentiment, thereby affecting financial stability. Since 2019, the global political and economic situation has become more complex and severe, and the external uncertainty facing China's economic and financial system has increased. In addition, the outbreak of the COVID-19 pandemic has had an unprecedented impact on China and the global economy. At the international level, international trade and investment have decreased. In addition, market volatility in risky assets such as stocks, bonds and commodities has increased. Furthermore, uncertain factors such as international economic and trade frictions and geopolitical evolution have intensified significantly. As finance is the most important aspect of a country's economy, maintaining financial stability has become a significant task not only related to economic development but also conducive to social stability.

Over the more than 40 years of China's reform and opening up efforts, the country's economic aggregate has grown rapidly, and its GDP ranks second in the world. In 2019, China's GDP reached \$14.36 trillion, ranking the second highest after that of the United States. However, the impact of events occurring in the external environment, such as Britain exiting from the EU and trade frictions between China and the United States, has led to global economic and financial turmoil. In addition, due to impacts of the recent pandemic, financial stability in China is facing new challenges. First, the risk of debt default faced by private enterprises and small and microscale enterprises may increase. Second, financial risks may lag, and there will be upwards pressure on nonperforming loans in later periods. Third, there are still great uncertainties in development trends and impacts. As an emerging market, China has an imperfect financial system. Therefore, the country is vulnerable to external shocks worldwide. In response to the uncertain state of the global economy, China has adopted a range of policies to maintain financial stability and social progress. With the deepening of structural reforms on the supply side, China's economic structure has undergone profound changes. Thus, ensuring reasonable investment has become the most important facet of China's path towards economic power. Hence, facing the dual challenges of internal changes and external shocks while ensuring reasonable government intervention, rational investment by investors and financial stability are issues that must be explored. 
Unlike previous studies, this paper focuses on the following aspects. First, to compensate for the defects of subjective and objective weighting, we apply an entropy weight-analytic hierarchy process to construct a financial stability index, which is seldom applied in existing studies (Brave and Butters 2011; Arzamasov and Penikas 2014; Liu et al. 2019). Second, previous scholars have only analyzed the relationships between two of the three variables (e.g., economic policy uncertainty and investor sentiment, economic policy uncertainty and financial stability and investor sentiment and financial stability), while no work has included the above three variables in a single model (Onour 2015; Niţoi and Pochea 2020). Third, many scholars have only considered linear effects while time varying relationships between economic policy uncertainty, investor sentiment and financial stability have been ignored. Therefore, we use a time varying parameter-vector autoregression model to describe dynamic correlations for different ahead periods and time points. Via empirical testing, it can be concluded that economic policy uncertainty has a significant negative correlation with investor sentiment before 2012 and with financial stability in the short term. In addition, the stock market disaster occurring in 2015 had a strong impact on the relationships between economic policy uncertainty, investor sentiment and financial stability. Next, we demonstrate the mediating effect of investor sentiment. In conclusion, our investigations can help the Chinese government better monitor investor sentiment to make timely adjustments to the implementation of policies. In addition, in ensuring financial stability, this paper can help the Chinese government predict different levels of economic development and then affect investor sentiment through different policies. This study proceeds as follows. Section 2 presents a literature review; Sect. 3 presents our methodology; Sect. 4 describes our data; Sect. 5 presents our empirical findings; and Sect. 6 concludes the study.

\section{Literature review}

\subsection{Investor sentiment and financial stability}

The correlation between investor sentiment and financial stability has been explored by numerous scholars. Matsusaka and Sbordone (1995) believe that when the investor factor is added to the macroeconomic model, simultaneous fluctuations occur in the financial system. Baker and Wurgler (2006) find that investors with a positive attitude in the market invest funds in high-risk and return stocks, affecting the financial market. A negative attitude can predict financial stability during an economic recession. In addition, there are interaction between different countries. Ling and Wang (2018) prove that changing investor sentiment in the United States can change financial stability in China during a financial crisis. Zhu and Chen (2019) reveal that the contagion efficiency of investor sentiment in China had a significant impact on the financial industry in the United States in 2008. Some scholars have analyzed the impact of financial stability on investor sentiment. Niţoi and Pochea (2020) find that when there is a certain shock in the financial market, strong feedback on investor sentiment may occur. As an important facet of financial stability, the banking system has been studied. Hussein (2016) finds that the stability of the banking system is reflected in risk 
characteristics such as bank runs and insufficient liquidity, which affect customers and reflect investor sentiment. Barbu and Boitan (2018) suggest that an increase in the nonperforming loan ratio leads to uncertainty in the financial market, which is not conducive to improving investor sentiment.

\subsection{Economic policy uncertainty and investor sentiment}

Due to the effect of economic policy uncertainty on investor sentiment, many scholars have contributed to the discussion of both micro- and macrolevel aspects. From a microlevel perspective, Jin (2008) conducts an analysis from the perspective of enterprise investment and finds that economic policy uncertainty makes investors prone to having a biased perception of risk, thereby leading to depression. Gilchrist et al. (2014) show that an increase in economic policy uncertainty has allowed banks to reduce risk by reducing credit supply, thus impacting the enthusiasm of investors. Zhang (2016), by studying the relationship between monetary policy and enterprise risk taken under the mediating effect of investor sentiment, concludes that policies can cause individual differences in investor sentiment among enterprises of different sizes and properties. Through a macrolevel study, Wang and Wang (2020) reveal that economic policy uncertainty has a negative impact on investor sentiment, which can increase the risk aversion of investors. The relationship between investor sentiment and economic policy uncertainty has also been studied. Rao et al. (2017) find that investors with pessimistic expectations of the future can cause companies to delay or reduce investment, making policies less effective. Furthermore, Zou and Tong (2015), by analysing media reports and bank risk, conclude that investor sentiment has a mediating effect on policy transmission.

\subsection{Economic policy uncertainty and financial stability}

From the perspective of financial instability, most scholars research the impact of economic policy uncertainty on financial stability. Pastor and Veronesi (2012), through a study of economic policy uncertainty and the stock market, show that when economic policy uncertainty is high, the stock yield is reduced, and a change in policy increases the volatility of the financial system. However, Lin (2014) proves that economic policy uncertainty has a positive effect on stock prices from cross-sectional and time series data. Onour (2015) comes to the same conclusion and suggests that a decline in economic policy uncertainty results in a country breaking two independent parts, which may lead to adverse long-term export shocks, eventually threatening financial stability. In reference to China, Zhang and Zhao (2017), by analysing the trading data of the Shanghai and Shenzhen Stock Exchanges, point out that economic policy uncertainty has effects on the time-lag effect of stock prices. According to Sun (2018), as economic policy uncertainty gradually increases, the systemic risk of the banking industry can significantly increase due to market fluctuations and financing liquidity. Furthermore, Pan et al. (2020) find that bank risk-taking plays a pivotal role as a financial stabilizer, while economic policy uncertainty affects risk-taking and further improves the investment behavior of enterprises. 
Previous studies mainly focus on the relationships between two variables, and few studies include economic policy uncertainty, investor sentiment and financial stability in the same model. In addition, most scholars only analyze the one-way influence between variables, and few study two-way relationships. Moreover, the mediating effect of investor sentiment has not been deeply discussed. Additionally, previous studies do not take time varying parameters of empirical models into account, resulting in nonconstant interaction between economic policy uncertainty, investor sentiment and financial stability being ignored. Therefore, this paper applies the time varying parameter-vector autoregression model to investigate the time varying effects between economic policy uncertainty, investor sentiment and financial stability and then provides evidence of the mediating effect of investor sentiment.

\section{Methodology}

This section first introduces the entropy weight-analytic hierarchy process used in the construction of the financial stability index. This method can overcome the objective weighting problem caused by the entropy weight method, and the subjective weighting problem caused by the analytic hierarchy process. In addition, we introduce a time-varying parameter-vector autoregressive model that lays the foundation for our empirical work.

\subsection{Entropy weight-analytic hierarchy process}

We first introduce the entropy weight method and analytic hierarchy process separately. On this basis, we further empower the weights obtained from the two to solve subjective and objective weighting problems.

\subsubsection{Entropy weight method}

Suppose there are $m$ objects and $n$ indicators, and the specific implementation steps are as follows.

First, matrix $x$ is obtained after dimensionless treatment. If $X_{z}$ is a positive index, it can be represented by $x_{z}=\left(X_{z}-\min \left(X_{z}\right)\right) /\left(\max \left(X_{z}\right)-\min \left(X_{z}\right)\right)$. If it is the reverse index, it can be expressed as $x_{z}=\left(\max \left(X_{z}\right)-X_{z}\right) /\left(\max \left(X_{z}\right)-\min \left(X_{z}\right)\right)$.

Second, the difference coefficient of index $z$ is solved. The first step is to use matrix $Y_{z}=x_{z} / \sum x_{z}$ to represent the specific gravity of each evaluation object. In the second step, the information entropy value of the evaluation index is solved, represented by $e_{z}=-k \sum_{i=1}^{m} y_{i z} \ln y_{i z}$. In the third step, difference coefficient $d_{z}$ can be obtained from $d_{z}=1-e_{z}$.

Finally, to calculate the weight of evaluation index $z$, we must use $w_{z}=$ $d_{z} /\left(\sum_{z=1}^{n} d_{z}\right)$ where $z \in[1, n]$.

\subsubsection{Analytic hierarchy process}

Assuming that there are $n$ evaluation indicators, the specific steps are as follows. 
Table 1 Values and meanings of judgement matrix $A$

\begin{tabular}{ll}
\hline Value of $A_{i z}$ & Value meaning \\
\hline 1 & $i$ is as important as $Z$ \\
$3(1 / 3)$ & $\begin{array}{c}i \text { is marginally more important } \\
\text { that } Z\end{array}$ \\
$5(1 / 5)$ & $i$ is more important that $Z$ \\
$7(1 / 7)$ & $i$ is more important that $Z$ \\
$9(1 / 9)$ & $i$ is significantly more important \\
& that $Z$ \\
$2,4,6,8,1 / 2,1 / 4,1 / 6,1 / 8$ & The specific value of the above \\
& meaning \\
\hline
\end{tabular}

First, judgement matrix $A$ of $n \times n$ is constructed. The values and meanings of $A$ are shown in Table 1.

Second, by calculating the maximum eigenvalue of judgement matrix $A$ obtained in the previous step and the maximum eigenvalue vector obtained after normalization, the weight represented by the $z$ evaluation index can be determined and denoted as $\theta_{z}$.

Finally, we perform a consistency test for matrix $A$. If it passes, it ends. However, if it does not, matrix $A$ needs to be adjusted, and the next step is performed again until the test is passed.

\subsubsection{Entropy weight-analytic hierarchy process}

The entropy-analytic hierarchy process combines the objective entropy weight method with the subjective analytic hierarchy process and uses the combined weight as the new weight value. According to relevant research results, the equation of combined weight is set as follows:

$$
U_{z}=\frac{w_{z} \times \theta_{z}}{\sum_{z=1}^{n} w_{z} \times \theta_{z}}
$$

where $U_{z}$ is the combined weight of solved evaluation index $Z . w_{z}$ and $\theta_{z}$ are the objective weight of the entropy weight method and the subjective weight of the analytic hierarchy process, respectively. Then, the comprehensive evaluation index is the product sum of the combination weight and the corresponding standardized value.

\subsection{Time varying parameter-vector autoregression model}

In the study of macroeconomic problems, the use of dynamic economic modeling methods has become a trend. Primiceri (2005) proposed the time varying parametervector autoregression model with random fluctuations as a means to overcome the limitations of the traditional vector autoregression model.

The interactions among variables can be examined by the vector autoregression model, but the coefficients and covariance should be stable. The standard structural 
vector autoregression model is defined as follows:

$$
A y_{t}=F_{1} y_{t-1}+\ldots+F_{s} y_{t-s}+\mu_{t}, t=s+1, \ldots, n
$$

where $A$ represents the coefficient matrix of the contemporaneous relationships between variables, $y_{t}$ is the dependent variable, $F_{1}, \ldots, F_{s}$ represents the coefficient matrix of the lag period, and $\mu_{t}$ is the structural impact of the model. Let $\mu_{t} \sim N(0, \Sigma \Sigma)$ where

$$
\Sigma=\left(\begin{array}{cccc}
\sigma_{1} & 0 & \ldots & 0 \\
0 & \ddots & \ddots & \ddots \\
\vdots & \ddots & \ddots & 0 \\
0 & \ldots & 0 & \sigma_{k}
\end{array}\right)
$$

We simplify the definition of the structural vector autoregression model as follows:

$$
y_{t}=B_{1} y_{t-1}+\ldots+B_{s} y_{t-s}+A^{-1} \Sigma \varepsilon_{t}
$$

where $B_{i}=A^{-1} F_{i}, i=1, \ldots, s, \varepsilon_{t} \sim N\left(0, I_{k}\right)$.

Stacking matrix $B_{i}$ is written as $k^{2} s \times 1$-dimensional vector $\beta$, and $X_{t}=I_{k} \otimes$ $\left(y_{t-1}^{\prime}, \ldots, y_{t-s}^{\prime}\right)$ is defined where $\otimes$ is the Kronecker product. Then, Eq. (3) can be further converted to the following:

$$
y_{t}=X_{t} \beta+A^{-1} \Sigma \varepsilon_{t}
$$

Let $a_{t}=\left(a_{21, t}, a_{31, t}, a_{32, t}, a_{41, t}, \ldots, a_{k k-1 t}\right)^{\prime}$ be a column vector of $A_{t}$ then, let $h_{t}=\left(h_{1 t}, \ldots, h_{k t}\right)^{\prime}, j=1, \ldots, k, t=s+1, \ldots, n$. In addition, it can be assumed that the parameters in Eq. (4) are subject to first-order random walk processes, which are shown in Eqs. (5) to (8). Where $\beta_{s+1} \sim N\left(\mu_{\beta_{0}}, \Sigma_{\beta_{0}}\right), \alpha_{s+1} \sim N\left(\mu_{\alpha_{0}}, \Sigma_{\alpha_{0}}\right), h_{s+1} \sim$ $N\left(\mu_{h_{0}}, \Sigma_{h_{0}}\right)$.

$$
\begin{gathered}
\beta_{t+1}=\beta_{t}+\mu_{\beta t} \\
\alpha_{t+1}=\alpha_{t}+\mu_{\alpha t} \\
h_{t+1}=h_{t}+\mu_{h t} \\
\left(\begin{array}{l}
\varepsilon_{t} \\
\mu_{\beta t} \\
\mu_{\alpha t} \\
\mu_{h t}
\end{array}\right) \sim N\left(0,\left(\begin{array}{cccc}
I & 0 & \ldots & 0 \\
0 & \Sigma_{\beta} & \ddots & \vdots \\
\vdots & \ddots & \Sigma_{\alpha} & 0 \\
0 & \ldots & 0 & \Sigma_{h}
\end{array}\right)\right)
\end{gathered}
$$


Since the stochastic volatility term in the time varying parameter-vector autoregression model is an unstable factor, using the maximum likelihood estimation method for parameter estimation is not advisable. Therefore, this paper uses the Markov chain Monte Carlo algorithm to estimate the parameters. The prior distribution of each parameter in Eq. (8) is set as $\left(\Sigma_{\beta}\right)_{i i}^{-2} \sim \Gamma\left(20,10^{-4}\right),\left(\Sigma_{\alpha}\right)_{i i}^{-2} \sim$ $\Gamma\left(4,10^{-4}\right),\left(\Sigma_{h}\right)_{i i}^{-2} \sim \Gamma\left(4,10^{-4}\right)$ where $\left(\Sigma_{\beta}\right)_{i i},\left(\Sigma_{\alpha}\right)_{i i}$ and $\left(\Sigma_{h}\right)_{i i}$ mean that the diagonal element of the matrix is $i$. According to the marginal likelihood function, the lag order is selected as lag 1 period, and the intercept term does not change with time. Before applying the Markov Chain Monte Carlo algorithm for empirical simulation, it is necessary to assign values to the parameters. Let $\mu_{\beta_{0}}=\mu_{a_{0}}=\mu_{h_{0}}=0$, $\Sigma_{\beta_{0}}=\Sigma_{a_{0}}=10 I, \Sigma_{h_{0}}=100 I,\left(\Sigma_{\beta}\right)_{i}^{-2} \sim \operatorname{Gamma}(20,0.01),\left(\Sigma_{\alpha}\right)_{i}^{-2} \sim$ $\operatorname{Gamma}(20,0.01)$ and $\left(\Sigma_{h}\right)_{i}^{-2} \sim \operatorname{Gamma}(20,0.01)$.

\section{Data}

This paper uses quarterly data for 2003:Q4 to 2020:Q4 to investigate the dynamic relationships between economic policy uncertainty, investor sentiment and financial stability in China and to further explore the mediating effect of investor sentiment. The China Banking Regulatory Commission was established in 2003 to supervise banking financial institutions. Therefore, the financial industry has entered a new era of more thorough supervision. In addition, during the severe acute respiratory syndrome coronavirus outbreak in 2003, macroeconomic policies focused on industries more heavily affected by the outbreak. Faster monetary expansion does not adjust until the economic growth trend is fully restored at the end of 2003:Q3. Hence, the data are for 2003:Q4.

Our use of the economic policy uncertainty index is mainly based on the research results of Baker et al. (2016). By counting terms related to policy uncertainty included in the South China Morning Post, the three scholars calculate the proportion of corresponding numbers of articles of all articles published in a given month and then standardize this value to obtain China's economic policy uncertainty index. Since the quarterly economic policy uncertainty index is used in this paper, the monthly economic policy uncertainty index is averaged. In addition, the investor sentiment index is based on the results of Baker and Wurgler (2012). Through a principal component analysis, the two scholars synthesize six variables ${ }^{1}$ and use the first principal component as a comprehensive indicator of investor sentiment. Furthermore, Baker and Wurgler (2012) take the median value of the monthly composite index of investor sentiment as a benchmark, where any value higher than the median value denotes high investor sentiment, and any value lower than the median value denotes low investor sentiment. Similar to what is done to obtain the economic policy uncertainty index, since this paper uses quarterly data, we first sum the monthly data to obtain quarterly data and then average the result to obtain the quarterly investor sentiment index. For the measurement of financial stability, based on current development trends in China

\footnotetext{
${ }^{1}$ The variables include the IPO number, IPO first-day yield, dividend premium, market turnover rate, closed-end fund discount rate and stock financing ratio.
} 
Table 2 Weight values of the entropy weight-analytic hierarchy process

\begin{tabular}{|c|c|c|c|}
\hline & $\begin{array}{l}\text { Entropy } \\
\text { weight }\end{array}$ & $\begin{array}{l}\text { Analytic hierarchy } \\
\text { process }\end{array}$ & $\begin{array}{l}\text { Entropy weight-Analytic } \\
\text { hierarchy process }\end{array}$ \\
\hline $\begin{array}{l}\text { Interest Rate Difference } \\
\text { Between Deposits and } \\
\text { Loans }\end{array}$ & 0.218 & 0.189 & 0.234 \\
\hline Ratio of Deposits and Loans & 0.021 & 0.040 & 0.005 \\
\hline $\begin{array}{l}\text { Nonperforming Loan Ratio } \\
\text { of Commercial Banks }\end{array}$ & 0.165 & 0.198 & 0.186 \\
\hline Price Earnings Ratio & 0.031 & 0.026 & 0.005 \\
\hline $\begin{array}{l}\text { Ratio of the Total Market } \\
\text { Value of Stocks to GDP }\end{array}$ & 0.087 & 0.081 & 0.040 \\
\hline Exchange Rate Index & 0.054 & 0.06 & 0.018 \\
\hline $\begin{array}{l}\text { Ratio of Domestic Credit to } \\
\text { GDP }\end{array}$ & 0.103 & 0.146 & 0.086 \\
\hline $\begin{array}{l}\text { Commercial Housing Sales } \\
\text { Price }\end{array}$ & 0.018 & 0.015 & 0.002 \\
\hline Inflation Rate & 0.218 & 0.248 & 0.427 \\
\hline
\end{tabular}

and from the literature, we find that it is not convincing to measure financial stability from a single index. Therefore, the entropy weight-analytic hierarchy process, which can combine subjective and objective weights, is used to construct a comprehensive index of financial stability. Referring to Morales and Estrada (2010), Brave and Butters (2011), Arzamasov and Penikas (2014), Xu et al. (2017), Liu et al. (2019), etc., the financial stability index system is constructed by selecting nine single indicators. ${ }^{2}$ The weight values used for the entropy weight-analytic hierarchy process are shown in Table 2.

All of the variables used in this paper are listed in Table 3. We take China as our research object and draw data from the Wind Database, China Stock Market \& Accounting Research Database, National Bureau of Statistics of China, China Foreign Exchange Trade System and Economic Policy Uncertainty Database.

Table 4 shows the statistical results. The mean values of economic policy uncertainty, investor sentiment and financial stability are 0.037, 0.011 and 0.004, respectively. The skewness of the above time series is positive and is presumed to distribute to the right. Additionally, the kurtoses of economic policy uncertainty, investor sentiment and financial stability are greater than 3 ; hence, these three variables satisfy the leptokurtic distributions, which feature a much higher peak compared to that of the normal distribution. To prevent heteroscedasticity and instability, we take the first logarithm differences of economic policy uncertainty, investor sentiment and financial stability.

\footnotetext{
${ }^{2}$ We use the interest rate difference between deposits and loans, the ratio of deposits and loans, nonperforming loan ratio of commercial banks, Price Earnings Ratio, ratio of the total market value of stocks to GDP, exchange rate index, ratio of domestic credit to GDP, commercial housing sales price and inflation rate to form a financial stability composite index.
} 
Table 3 Variable sources and basic descriptions

\begin{tabular}{|c|c|c|}
\hline & Sources & Description \\
\hline $\begin{array}{l}\text { Interest Rate Difference Between } \\
\text { Deposits and Loans }\end{array}$ & $\begin{array}{l}\text { National Bureau of Statistics } \\
\text { of China }\end{array}$ & $\begin{array}{l}\text { Loan interest minus deposit } \\
\text { interest }\end{array}$ \\
\hline Ratio of Deposits and Loans & Wind & $\begin{array}{l}\text { Total amount of loans/total } \\
\text { amount of deposits }\end{array}$ \\
\hline $\begin{array}{l}\text { Nonperforming Loan Ratio of } \\
\text { Commercial Banks }\end{array}$ & $\begin{array}{l}\text { National Bureau of Statistics } \\
\text { of China }\end{array}$ & $\begin{array}{l}\text { Nonperforming loans are } \\
\text { mainly substandard loans, } \\
\text { doubtful loans and loss } \\
\text { loans }\end{array}$ \\
\hline Price Earnings Ratio & Wind & $\begin{array}{l}\text { Stock price/earnings per } \\
\text { share }\end{array}$ \\
\hline $\begin{array}{l}\text { Ratio of the Total Market Value of } \\
\text { Stocks to GDP }\end{array}$ & $\begin{array}{l}\text { National Bureau of Statistics } \\
\text { of China }\end{array}$ & $\begin{array}{l}\text { The total market value of the } \\
\text { stocks of listed companies } \\
\text { in China is used }\end{array}$ \\
\hline Exchange Rate Index & $\begin{array}{l}\text { China Foreign Exchange Trade } \\
\text { System }\end{array}$ & $\begin{array}{l}\text { Changes in the weighted } \\
\text { average exchange rate of a } \\
\text { country's currency to a } \\
\text { basket of foreign currencies }\end{array}$ \\
\hline Ratio of Domestic Credit to GDP & Wind & $\begin{array}{l}\text { Domestic credit refers to } \\
\text { loans issued to domestic } \\
\text { enterprises or individuals }\end{array}$ \\
\hline Commercial Housing Sales Price & $\begin{array}{l}\text { China Stock Market \& } \\
\text { Accounting Research } \\
\text { Database }\end{array}$ & $\begin{array}{l}\text { Actual transaction price } \\
\text { between the buyer and } \\
\text { seller when ownership of } \\
\text { the property is transferred }\end{array}$ \\
\hline Inflation Rate & Wind & $\begin{array}{l}\text { The part of the currency } \\
\text { overissued/the actual } \\
\text { amount of currency needed }\end{array}$ \\
\hline Economic Policy Uncertainty & $\begin{array}{l}\text { Economic Policy Uncertainty } \\
\text { Database }\end{array}$ & $\begin{array}{l}\text { Monthly data for China } \\
\text { averaged on a quarterly } \\
\text { basis }\end{array}$ \\
\hline Investor Sentiment & $\begin{array}{l}\text { China Stock Market \& } \\
\text { Accounting Research } \\
\text { Database }\end{array}$ & $\begin{array}{l}\text { Monthly data for China } \\
\text { averaged on a quarterly } \\
\text { basis }\end{array}$ \\
\hline
\end{tabular}

Table 4 Basic statistical characteristics of the sample data

\begin{tabular}{lllllll}
\hline & Mean & Maximum & Minimum & Std & Skewness & Kurtosis \\
\hline Economic policy uncertainty & 0.017 & 0.926 & -0.723 & 0.351 & 0.211 & 3.119 \\
Investor sentiment & 0.014 & 0.712 & -0.649 & 0.224 & 0.335 & 5.141 \\
Financial stability & 0.012 & 0.369 & -0.271 & 0.131 & 0.539 & 3.235 \\
\hline
\end{tabular}


Table 5 Partial parameter estimation results

\begin{tabular}{lllllll}
\hline Parameter & Mean & Std & $\begin{array}{l}95 \% \text { Upper } \\
\text { bound }\end{array}$ & $\begin{array}{l}95 \% \text { Lower } \\
\text { bound }\end{array}$ & Geweke & Invalid factor \\
\hline$\left(\Sigma_{\beta}\right)_{1}$ & 0.023 & 0.003 & 0.018 & 0.029 & 0.555 & 3.240 \\
$\left(\Sigma_{\beta}\right)_{2}$ & 0.023 & 0.003 & 0.018 & 0.028 & 0.935 & 5.050 \\
$\left(\Sigma_{a}\right)_{1}$ & 0.072 & 0.025 & 0.040 & 0.135 & 0.008 & 25.730 \\
$\left(\Sigma_{a}\right)_{2}$ & 0.084 & 0.034 & 0.042 & 0.172 & 0.895 & 26.170 \\
$\left(\Sigma_{h}\right)_{1}$ & 0.283 & 0.118 & 0.115 & 0.570 & 0.237 & 36.330 \\
$\left(\Sigma_{h}\right)_{2}$ & 0.262 & 0.155 & 0.072 & 0.671 & 0.185 & 37.020 \\
\hline
\end{tabular}

\section{Empirical results}

\subsection{Markov Chain Monte Carlo algorithm validity test}

In this paper, the Markov Chain Monte Carlo algorithm is used to iterate 10,000 times, and the first 1000 times are discarded to obtain the posterior distribution of Markov Chain convergence. Furthermore, the mean estimation of each parameter is obtained by sampling, and the effectiveness of the Markov Chain Monte Carlo algorithm is tested according to Geweke and invalid factors.

From Table 5, which demonstrates the parameter estimation, it can be concluded that the standard deviation of each parameter is small, especially when the first four parameters are less than the alpha level of 0.05 . Moreover, the $95 \%$ confidence interval indicates that the estimation of each parameter is significant. According to the Geweke results, the null hypothesis that the parameters converge to a posterior distribution is rejected at the significance level of $10 \%$. Furthermore, the invalid factors are less than 50, which suggests that the samples extracted by the Markov Chain Monte Carlo algorithm are available. The model conforms to the Bayesian deviation information criterion, which further proves the robustness of the Markov Chain Monte Carlo algorithm.

Based on the Markov Chain Monte Carlo algorithm, we performed parameter simulations, and the results are shown in Fig. 1. The top row shows the sample autocorrelation diagram, which demonstrates that the sample coefficient decreases rapidly with each simulation and finally converges to 0 . In addition, the sample path diagram presented in the middle row shows that it fluctuates at the mean value, presenting a pattern of fluctuation clustering. The bottom row showing the posterior density distribution diagram illustrates that the parameters obey the posterior distribution and convergence criterion. These results further indicate that the estimated value based on the Markov Chain Monte Carlo algorithm is robust and reliable.

\subsection{Empirical analysis}

We further analyze the impulse response graph of economic policy uncertainty, investor sentiment and financial stability. The time-lag effect of economic policy uncertainty, 

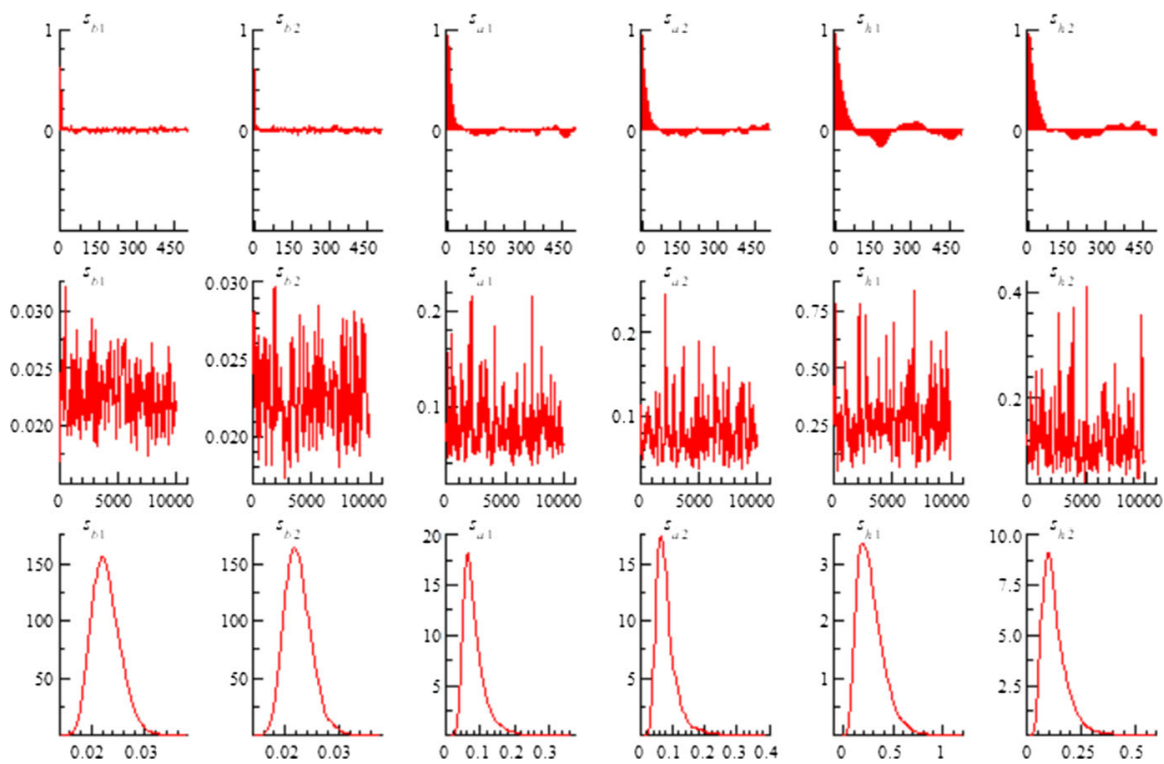

Fig. 1 Markov chain Monte Carlo algorithm simulation parameter diagram

investor sentiment or financial stability is shown by the pulse of different ahead periods, with one quarter in advance (the red curve) used to measure the short term and three (the purple curve) and six quarters (the green curve) in advance used to indicate the medium and long terms, respectively.

Figure 2 reveals the influence of economic policy uncertainty on investor sentiment, financial stability and itself. Regarding the positive impact of economic policy uncertainty, the financial stability of each ahead period is negative. The outbreak of the financial crisis burst of the real estate bubble, mainly because of the increasing default rate of the United States subprime housing credit industry and other causes of international financial market shocks, panic and crises. The general spread of uncertainty is also one of the most notable features of economic depression. Under this severe international setting, China has adopted a range of monetary and fiscal policies to increase growth and stabilize employment by cutting taxes, expanding government spending
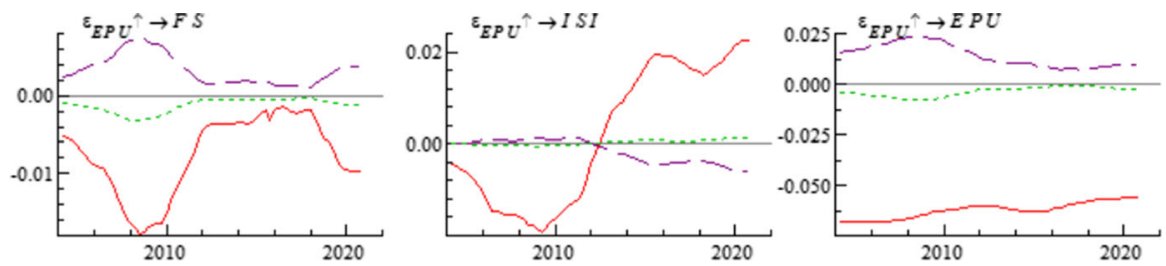

Fig. 2 Impulse response of economic policy uncertainty to investor sentiment, financial stability and itself. $E P U$ indicates economic policy uncertainty, FS indicates financial stability, and ISI indicates investor sentiment. (The following figures apply the same parameters) 
and guiding the central bank to issue bills to ensure a liquidity supply. Accordingly, uncertainty may delay the investment and consumption of economic entities, resulting in increased exchange rate fluctuations and eventually affecting financial stability. Therefore, the frequent release of policies has caused turbulence in the financial market, further resulting in an unstable financial situation in the short term.

Furthermore, economic policy uncertainty has a negative impact on investor sentiment in the short term before 2012. While economic policy uncertainty increased from 2008 to 2010, the impact on investor sentiment strengthened. In the first half of 2008, the People's Bank of China adjusted the Renminbi deposit reserve ratio of depository financial institutions from 15 to $17.5 \%$. In 2009, the Chinese government continued to implement expansionary fiscal and monetary policies as well as a comprehensive callback trade policy. The policies caused the national economy fluctuate, causing investors to have generally lower market expectations. During the stock market crash in 2015, the Chinese government adopted a number of policies (e.g., reducing reserve requirements and interest rates, circuit breaker mechanisms, limiting empty orders of stock index futures, etc.) to rescue the market, resulting in the Chinese government increasing investor confidence in the market through continuous policy regulation. In 2017, after Donald J. Trump took office as President of the United States, the frequency of issuing policies increased significantly. Meanwhile, the United States withdrew from the Trans-Pacific Partnership and Paris Agreement, launched a "301 investigation" against China, and suppressed Chinese technology companies (e.g., Huawei). China had to issue various policies (e.g., circuit breaker mechanisms and restricted empty futures orders) to deal with these harsh external processes, increasing investor confidence in the Chinese government and causing investor sentiment to increase.

Figure 3 shows the influence of investor sentiment on economic policy uncertainty, financial stability and itself. Before 2010, investor sentiment had a gradually positive impact on financial stability, while after 2010, the positive impact gradually weakened. From 2004 to 2008, investors made continuous and active transactions in the financial market. Thus, investor sentiment is positively correlated with financial stability. With the financial crisis caused by the subprime mortgage crisis, investors grew frustrated with the market, not only reducing their investment, but also leading to their funds being tied up in the market, resulting in extreme instability in the financial system. After 2010, as the effect of the financial crisis gradually faded, securities investment was prevalent, and irrational sentiment was rampant, creating risks of bubble formation. Additionally, with the stock market crash in 2015, investors lost all confidence in the
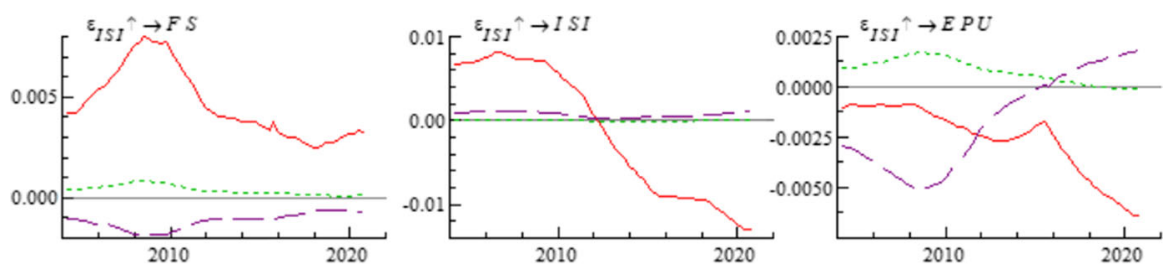

Fig. 3 Impulse response of investor sentiment to financial stability, economic policy uncertainty and itself 

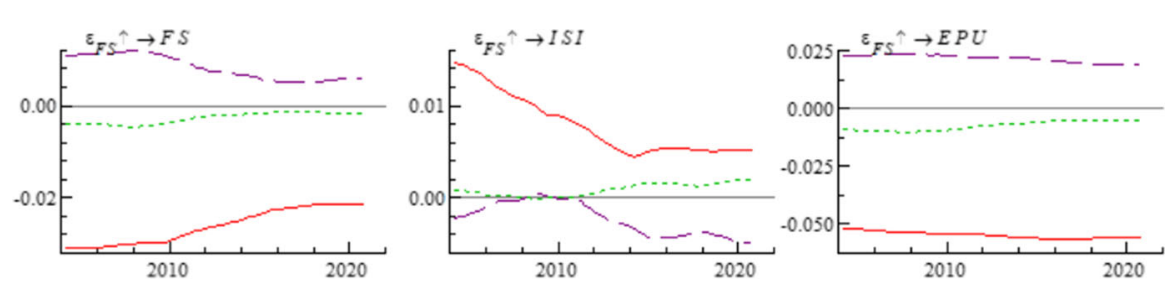

Fig. 4 Impulse response of financial stability to economic policy uncertainty, investor sentiment and itself

market, and financial instability reached its maximum level. Furthermore, from the start of trade disputes between China and the United States in 2008 to the onset of the COVID-19 pandemic in 2020, investors were not optimistic about the international situation, which led to a decline in investor sentiment and made the entire financial market appear unstable.

Investor sentiment has a large and persistent negative impact on economic policy uncertainty in the short term. Before the subprime mortgage crisis, investors were active in financial markets. The government did not adopt policies and measures frequently, which meant that economic policy uncertainty was lower. After 2008, due to high investor sentiment in early stages, irrational investment was prevalent. This led to a large number of bubbles forming in the global market, and China was also deeply affected. With the financial crisis, investors became disillusioned with the market; thus, the government adopted the Ten Industry Revitalization Plan ${ }^{3}$ to address the impact of the international financial crisis on the real economy. In addition, the Four Trillion Stimulus Plan ${ }^{4}$ was adopted a powerful means for the government to expand domestic demand and promote stable economic growth. Therefore, investor sentiment has a negative impact on economic policy uncertainty. In the medium term, augmentation of investor sentiment has mixed effects on economic policy uncertainty, which signifies that the influence of investor sentiment on economic policy uncertainty shows some continuity, but the impact diminishes in the long term.

Figure 4 shows the influence of financial stability on economic policy uncertainty, investor sentiment and itself. Before 2008, the size and activity of the financial market grew steadily, and financial market products and trading models were constantly innovated. Therefore, the Chinese government pursued less intervention in the economy, and fiscal and monetary policies were reduced. The impact of the subprime mortgage crisis on China was mainly reflected in the banking and other financial industries, which had purchased numerous United States bonds (e.g., Bank of China, China Construction Bank, Ping An Insurance, etc.). However, with the collapse of Bank of America, China's financial industry suffered major losses as a whole. Consequently, to expand domestic demand and ensure the smooth operation of the economy, the government issued a series of policies. Hence, the decrease in financial instability led to a rise in economic policy uncertainty. Following the stock market crash in 2015 and

\footnotetext{
3 The plan focuses on the steel, automobile, ship, petrochemical, textile, light industry, nonferrous metal, equipment manufacturing, electronic information and logistics sectors.

4 To address the impact of the financial crisis, the Chinese government had spent approximately 4 trillion yuan in investment in related measures by the end of 2010 .
} 
trade disputes between China and the United States in 2018, finance developed in an oscillating manner. In 2015, the Ministry of Finance of China helped ten institutions ${ }^{5}$ set up government and social capital cooperation financing support funds amounting to 180 billion yuan. However, with the trade war that began in 2018, the monetary policy of the domestic central bank failed to follow the Fed's gradual tightening of the currency, such as through the reduction of the deposit reserve ratio, the more frequent operation of open market lending facilities, and the augmentation of the investment of infrastructure construction investment loans. Hence, financial stability and economic policy uncertainty show an inverse relationship.

Financial stability has a positive impact on investor sentiment in the short term. Before 2008, the reasonable and orderly investment environment made the overall financial system stable, and investors had a positive view of the market. Consequently, the increase in financial stability had a positive impact on investor sentiment. Furthermore, after the outbreak of the financial crisis in 2008, financial stability and investor sentiment showed a positive correlation that continued to decline, which meant that when the entire financial system was turbulent, investors felt powerless to restore the market. After the national promulgation of relevant policies to restore the stability of the financial system, financial stability rebounded to a certain extent, and investors began to recover and build confidence in the future development of the financial system. Therefore, financial stability and investor sentiment are positively correlated.

Upon analysing the relationships between economic policy uncertainty, investor sentiment and financial stability, we find that government intervention in the economic and financial fields may not directly affect financial stability through policies. Moreover, it is found that investors' desire to participate in market investment can be a pivotal signal of economic and financial development. In response to changes in economic policies, investors react differently on the future of the market; therefore, their market expectations may be bullish or bearish. Based on their own expectations, investors change their investment strategies, which has a certain impact on the stability of the financial system. Conversely, financial stability influences economic policy uncertainty through investor sentiment. When financial stability improves, investors have more investment enthusiasm, and they are active in investment markets. Meanwhile, because the participation of investors injects vitality into the financial market, the state will promulgate fewer policies to intervene in the economy. However, once enthusiasm increases a certain degree, there is a large-scale "herd effect", 6 and the government takes policy measures to curb the emergence of financial system bubbles. When financial stability declines, investors reduce investment to avoid risks. Therefore, to increase domestic investment demand and promote the economy, the government issues a range of policies to intervene in the unstable financial system,

\footnotetext{
5 The institutions include China Construction Bank Co., Ltd., China Postal Savings Bank Co., Ltd., Agricultural Bank of China Co., Ltd., Bank of China Co., Ltd., China Everbright Group Co., Ltd., Bank of Communications Co., Ltd., Industrial and Commercial Bank of China, China CITIC Group Co., Ltd., National Council of Social Security Funds, and China Life Insurance (Group) Company.

6 The herd effect refers to the method of taking actions consistent with actions taken by several large companies in the same industry, thereby guiding the other party to take the same actions.
} 
augmenting economic policy uncertainty. Generally, investor sentiment can be considered a mediating variable in the correlation mechanism between economic policy uncertainty and financial stability.

By impacting one variable to obtain the response of other variables for different lag periods, we obtain the impulse response function for different time points. For different impulse response function graphs, the responses of economic policy uncertainty, investor sentiment and financial stability at different time points can be examined. The rationale behind our selection of time points is given in Table 6.

As shown in Fig. 5, at the lowest point of economic growth in 2009, 1 unit of positive impact is exerted on financial stability, causing itself and investor sentiment to decrease from 0.1 and 0.03 to close to 0 , respectively. When 1 unit of shock is applied to economic policy uncertainty, the impact on financial stability decreases from 0 to 0.01 and increases rapidly to 0.01 in the first two periods, indicating that the effect of economic policy on the overall financial environment fluctuates greatly. However, the

Table 6 Time points with corresponding economic events

\begin{tabular}{lll}
\hline Time point & Economic event & Representation \\
\hline 2009:Q1 & The lowest point of economic growth during the financial crisis & $t=21$ \\
2011:Q2 & Soft Economic Expansion & $t=30$ \\
2015:Q3 & The Stock Market Crash & $t=41$ \\
2020:Q1 & The COVID-19 Pandemic & $t=64$ \\
\hline
\end{tabular}
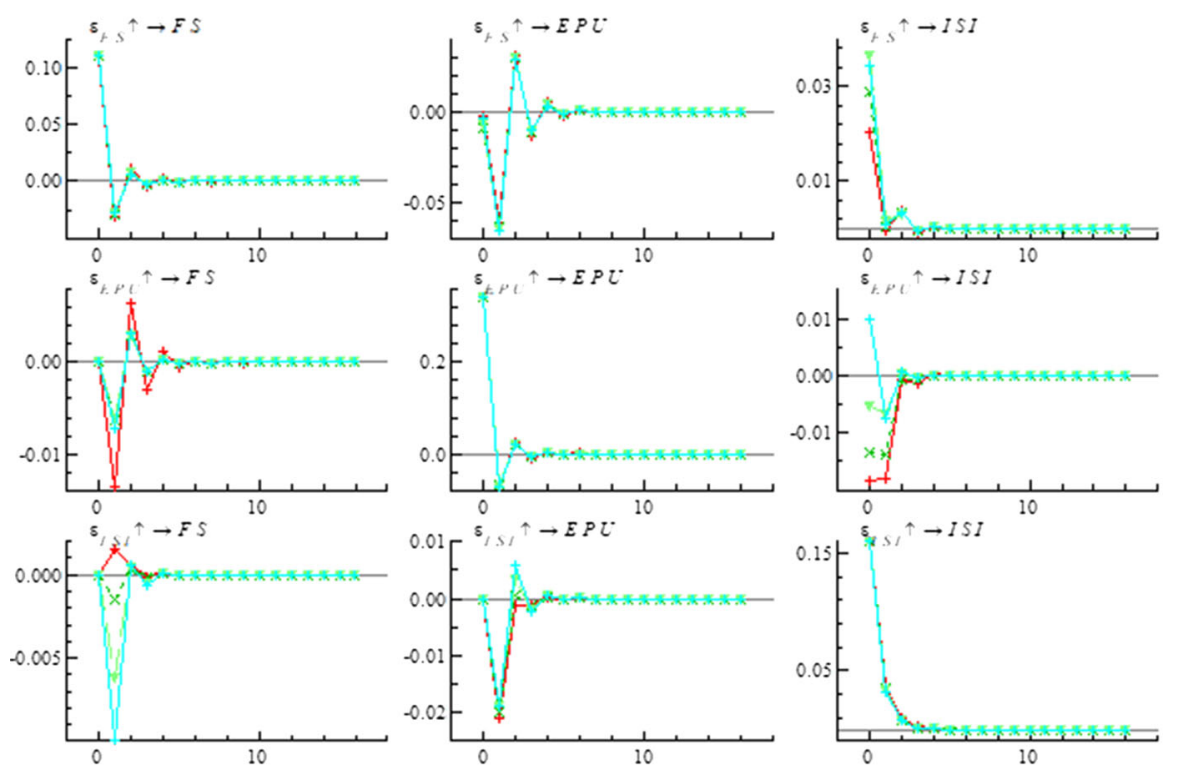

Fig. 5 Impulse response under the impacts of variables at different time points 
impact of economic policy uncertainty shows a sharp decline from approximately 0.3 to below 0 and rebounds to 0 before remaining relatively unchanged. Furthermore, the effect on investor sentiment rises sharply from -0.02 to approximately 0 and remains unchanged, indicating that economic policy uncertainty and investor sentiment exhibit reverse changes, and the effect weakens over time. When 1 unit of impact is applied to investor sentiment, the effect on financial stability is small, while economic policy uncertainty drops to -0.02 in the first two periods and then gradually rebounds to 0 and remains unchanged.

During the soft economic expansion stage of 2011:Q2, the effect of financial stability on itself, economic policy uncertainty and investor sentiment follow almost the same trend as that observed in 2009. When economic policy uncertainty is impacted by 1 unit, investor sentiment changes dramatically. However, the proactive fiscal and moderately loose monetary policies of 2011 have a less negative impact on investor sentiment than those of 2009. The main reason is that the 2008 financial crisis led to a global economic downturn; therefore, policies designed to rescue the market in 2009 played a stabilizing role for investors. In addition, the impact of investor sentiment on financial stability is positive in 2009 and negative in 2011, showing that as the economy gradually resumes expansion, investors become more active in the market. This means that investors' irrational and excessive investment behaviors prevail, leading to financial bubbles and thus to the risk of bubbles forming in the entire financial market.

During the stock market crash in 2015, a shock to economic policy uncertainty had a less impact on financial stability than in 2009. In 2015, investors had different interpretations of economic policies and expectations of the future. Hence, they had a wait-and-see view of the future of the financial system. Furthermore, the impulse response graph of economic policy uncertainty to investor sentiment indicates that the introduction of policies was attractive to some investors. However, the trend of gradual decline denotes that investors have expected future development prospects from the financial system, though the psychology of the actor is uncertain. This conclusion is drawn from the effect of investor sentiment on financial stability. Due to the sharp fluctuations of the economy, investors cannot develop clear expectations of the future; thus, investors use different investment strategies, resulting in fluctuations in financial markets.

With the onset of the COVID-19 pandemic, with economic policy uncertainty, investor sentiment and financial stability, the response is basically consistent with that of the financial crisis in early 2009, but the impact of 1 unit of shock on financial stability is more significant than the effect on investor sentiment. The main reason is that when the average daily increase in cases gradually decreases with the development of the pandemic, investors predict that the financial system will gradually recover and achieve greater growth, causing them to quickly invest in the financial market, which causes investor sentiment to increase rapidly. Consequently, the overall range of investor sentiment may be large, but the impact of changes over time tends to be 0 . Additionally, the impact of 1 unit on economic policy uncertainty has a less negative impact on investor sentiment than in 2009 and 2011. An obvious difference between this pandemic and the 2008 international financial crisis is that the latter involved a crisis of the financial system, while the 2020 pandemic involved a major public health incident that triggered a recession in the real economy, which in turn had an impact 
Table 7 Grange causality tests

\begin{tabular}{|c|c|c|c|}
\hline Null hypothesis & Obs & F-Statistic & Prob \\
\hline $\begin{array}{l}\text { Financial stability does not Granger Cause Economic policy } \\
\text { uncertainty }\end{array}$ & 67 & 0.578 & 0.045 \\
\hline $\begin{array}{l}\text { Economic policy uncertainty does not Granger Cause Financial } \\
\text { stability }\end{array}$ & & 3.771 & 0.028 \\
\hline $\begin{array}{l}\text { Investor sentiment does not Granger Cause Economic policy } \\
\text { uncertainty }\end{array}$ & 67 & 1.417 & 0.025 \\
\hline $\begin{array}{l}\text { Economic policy uncertainty does not Granger Cause Investor } \\
\text { sentiment }\end{array}$ & & 0.589 & 0.031 \\
\hline Investor sentiment does not Granger Cause Financial stability & 67 & 0.703 & 0.049 \\
\hline Financial stability does not Granger Cause Investor sentiment & & 0.647 & 0.005 \\
\hline
\end{tabular}

on the financial market. Therefore, in terms of policy guidance, the policies adopted during the epidemic period mainly affected the resumption of work and production of enterprises, stimulating domestic demand and achieving financial stability. In contrast, the 2008 policy directly affected the financial market, which has a more significant impact on investors.

\subsection{Robustness test}

To verify the robustness of the results, we use a Granger causality test to verify the causal relationships between economic policy uncertainty, investor sentiment and financial stability. The results are shown in Table 7 . We find a causal effect between any two of the three, which further validates the causal effects between economic policy uncertainty, investor sentiment and financial stability and supports our methods and results.

In general, we analyze the correlations between economic policy uncertainty, investor sentiment and financial stability. First, no scholars have used the entropy weight-analytic hierarchy process to construct financial stability indicators. As the entropy weight-analytic hierarchy process makes up for the defects of subjective and objective weighting, the comprehensive indicators are more consistent with reality. Therefore, the construction of the index increases measurement financial stability and provides new ideas for research on this kind of problem. Second, the parameter estimation and validity test prove that the sample of the Markov Chain Monte Carlo algorithm is effective and robust, and time varying parameters can highlight the defects of the vector autoregression model. Third, our results for different periods show that economic policy uncertainty has a significant negative correlation with investor sentiment before 2012 and with financial stability in the short term. Before 2010 , investor sentiment had a positive and gradually increasing impact on financial stability, while after 2010, the positive impact gradually weakened. In addition, the impact of financial stability on investor sentiment is positively correlated at all times. Additionally, in terms of mediating effects, investor sentiment plays a mediating role 
in the transmission of economic policy uncertainty and financial stability. Fourth, at four different time points, the responses of the three variables to different economic events are roughly similar. Finally, a Granger causality test verifies the causal relationships between economic policy uncertainty, investor sentiment and financial stability, and the results meet robustness requirements.

\section{Conclusions}

This paper constructs a comprehensive index to measure financial stability by the entropy weight-analytic hierarchy process. Then, economic policy uncertainty, investor sentiment and financial stability data are selected from 2003:Q4 to 2020:Q4. The time varying parameter-vector autoregression model can reflect the time varying relationships between economic policy uncertainty, investor sentiment and financial stability at different ahead periods and time points and can be used to analyze the mediating effect of investor sentiment. The empirical results show dynamic relationships between economic policy uncertainty, investor sentiment and financial stability. First, the relationship between economic policy uncertainty and investor sentiment is mixed with both positive and negative correlations. Second, economic policy uncertainty and financial stability have a negative effect on each other, and the negative impact of financial stability on economic policy uncertainty is similar at different time points, while the effect of economic policy uncertainty on financial stability is volatile at different time points. Third, investor sentiment and financial stability show a strong positive correlation in the short term. Fourth, we find that investor sentiment has a mediating effect on the interactions between economic policy uncertainty and financial stability. Finally, a Granger causality test verifies the robustness of our results.

Therefore, owing to the influence of economic policy uncertainty on investor sentiment and financial stability, the government should not only recognise that policies themselves affect the economy but also pay attention to the effect of the uncertainty caused by frequent policy changes on the financial system. Therefore, the government should fully consider whether policies conform to the actual operating rules of society and should be more concerned with the frequency of policy release and modification when making policies. In addition, the relevant state departments should improve the financial system by establishing and improving the financial market supervision system and laws to help investors regain confidence and maintain financial stability. Moreover, due to the pivotal role investor sentiment plays in the release of national policies and financial stability, the government should augment the quantity of institutional investors and popularize investment theories and risks for individual investors to encourage the reasonable investment and stability of the financial system.

In future research, we will verify the spillover effects of economic policy uncertainty, investor sentiment and financial stability in different countries or regions. In addition, we will further explore the financial stability indexes applicable to different countries or regions. 


\section{References}

Arzamasov V, Penikas H (2014) A financial stability index for Israel. Procedia Comput Sci 31:985-994

Baker M, Wurgler J (2006) Investor sentiment and the cross-section of stock returns. J Financ 61(4):1645-1680

Baker M, Wurgler J, Yuan Y (2012) Global, local, and contagious investor sentiment. J Financ Econ 104(2):272-287

Baker SR, Bloom N, Davis SJ (2016) Measuring economic policy uncertainty. Q J Econ 131(4):1593-1636

Barbu TC, Boitan I (2018) Confidence in european retail banking: assessing relationship with economic fundamentals. Ekonomicky Casopis 66(2):181-198

Brave SA, Butters R (2011) Monitoring financial stability: A financial conditions index approach. Econ Perspect 35(1):22

Gilchrist, S., Sim, J. W., \& Zakrajšek, E. (2014). Uncertainty, financial frictions, and investment dynamics (No. w20038). National Bureau of Economic Research.

Hussein, K. (2016). Bank-level stability factors and consumer confidence-A comparative study of Islamic and conventional banks' product mix. In Islamic Finance (pp. 86-104). Palgrave Macmillan, Cham.

Jin GH (2008) Fair information disclosure: comparison and reference. J Lanzhou Commer Coll 04:101-105

Lin JH, Li X, Li H (2014) An empirical study on the relationship between economic policy uncertainty and asset pricing in China. Ch Manag Sci 22(S1):222-226

Ling ZM, Wang JL (2018) Analysis of investor sentiment contagion based on Copula model variable point detection. Stat Decis-Mak 34(07):171-174

Liu SQ, Qi XZ, Qin M, Su CW (2019) Financial stability or instability? impact from chinese consumer confidence. J Econ Forecast 4:25-43

Matsusaka JG, Sbordone AM (1995) Consumer confidence and economic fluctuations. Econ Inq 33(2):296-318

Morales MA, Estrada D (2010) A financial stability index for Colombia. Ann Finance 6(4):555-581

Niţoi M, Pochea MM (2020) Time-varying dependence in European equity markets: a contagion and investor sentiment driven analysis. Econ Model 86:133-147

Onour I (2015) Modeling inflation dynamics in a conflict economy. University Library of Munich, Germany, MPRA Paper

Pan P, Deng C, Qiu Y (2020) Economic policy uncertainty, bank risk taking and enterprise investment. Financ Econ Res 46(02):67-81

Pastor L, Veronesi P (2012) Uncertainty about government policy and stock prices. J Financ 67(4):1219-1264

Primiceri GE (2005) Time varying structural vector auto-regressions and monetary policy. Rev Econ Stud 72(3):821-852

Rao PG, Yue H, Jiang GH (2017) Economic policy uncertainty and enterprise investment behavior. World Econ 40(02):27-51

Sun Q (2018) Research on the impact mechanism of economic policy uncertainty on systemic risk. Finance and Accounting Monthly 18:155-162

Wang YT, Wang SW (2020) Analysis on the impact of policy uncertainty on investor sentiment. Market Weekly 01:115-116

Xu GX, Guo JN, Chen RP (2017) The construction of China financial stability index and its leading ability analysis. Stat Inf Forum 32(04):27-33

Zhang QC (2016) Monetary tightening, financial flexibility and enterprise risk taking. Contemp Financ Econ 11:45-56

Zhang WL, Zhao MZ (2017) Policy uncertainty, price delay and equity returns. J Econ Res 06:58-60

Zhu WQ, Chen GX (2019) Contagion effect of investor sentiment in china and the united states and financial market stability. Bus Res 07:92-99

Zou J, Tong ZW (2015) Media reports, investor sentiment and bank risk taking-an empirical study based on china's listed banks. Financ Theory Pract 02:32-38

Publisher's Note Springer Nature remains neutral with regard to jurisdictional claims in published maps and institutional affiliations. 


\section{Authors and Affiliations}

\section{Xin-Zhou $Q i^{1} \cdot$ Zhong Ning ${ }^{2}$ - Meng Qin $^{3}$}

1 School of Management, Fudan University, 670, Guoshun Rd, Shanghai, China

2 School of Management, Fudan University, Shanghai, China

3 Department of Economics, Party School of the Central Committee of the Communist Party of China, Beijing, China 